\title{
Design aspirations for biomimicry and improved health outcomes: fusing a myriad of intellectual disciplines at Arizona state university
}

\section{Introduction}

More than a decade ago, Arizona State University (ASU) set forth an ambitious trajectory to become a global leader in producing interdisciplinary, multidisciplinary, transdisciplinary, and postdisciplinary scholars and scholarly research. ${ }^{1,2}$ Today, the Arizona State University and ASU Online design principle of "Fuse Intellectual Disciplines" applies directly to ASU student health, the ASU Biomimicry Center and their graduate programs. Currently, ASU offers the first Master of Science in Biomimicry of its kind in the world. ${ }^{3}$ As a Faculty Affiliate of ASU's Biomimicry Program; I am beyond thrilled that it has found a university to call home as it flourishes across multiple academic disciplines (Figure 1).

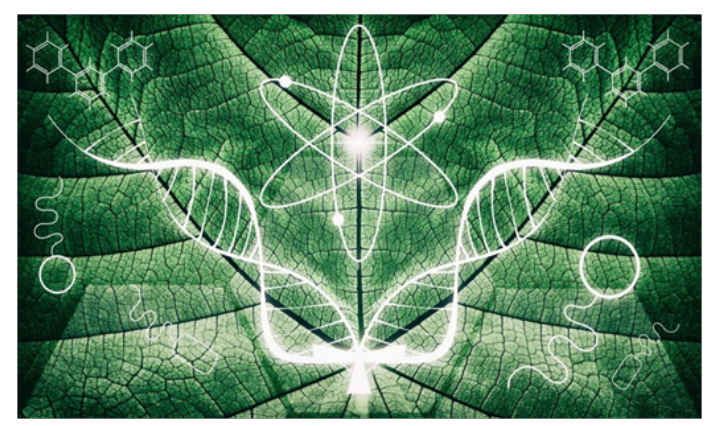

Figure I Biomimicry. Health Innovations Inspired by Nature. ${ }^{3}$

Seen through the lens of health literacy and biological literacy, biomimicry is the golden thread through many if not all the biology inspired fields. Biomimicry is generally referred to as learning from and emulating the genius of nature's forms, processes, and ecosystems to create more sustainable designs. ${ }^{3,4}$ Because biomimicry is an evolving field ${ }^{4}$ interdisciplinary collaboration is of import in advancing the discipline. The discipline is already growing rapidly as tools are being developed at the university level around distinct biomimicry methods and health related research questions. ${ }^{5}$ Notwithstanding, the methodology of biomimicry is closely related to Schools of Life Sciences, Schools of Health Solutions, Biology Departments and Design Departments.

\section{Fuse intellectual disciplines}

Through exploration, research and implementation of realworld interdisciplinary biomimicry models, my goal is to identify opportunities to decrease health conditions and improve overall health outcomes of the ASU student population. I selected "Fuse Intellectual Disciplines" as one of the eight ASU design aspirations that I am most interested in for fulfilling this goal. The ASU design aspiration "Fuse Intellectual Disciplines" is important to me because my behavioral health research, medicine related studies, and online teaching transcends several academic fields including but not limited to: behavioral health, biomimicry, communications, complementary medicine, computer science, criminology, digital media, exercise and sport science, gerontology, kinesiology, management and
Volume 12 Issue 4 - 2019

\author{
Robelyn A Garcia, \\ 'Arizona State University, USA \\ ${ }^{2}$ Harvard University, USA
}

Correspondence: Robelyn A Garcia, Arizona State University and Harvard University, USA,

Email Dr.RobelynGarcia@asu.edu, RoG8I4@g.harvard.edu

Received: July 02, 2019 | Published: July 24, 2019

administration, museum technology, post-secondary education, online higher education and therapeutic lifestyle change. I attempt to keep abreast of new developments in all my fields of study by continuously refreshing my knowledge of current research and literature in hopes of improving health outcomes of my clients and students.

The ASU design aspiration "Fuse Intellectual Disciplines" relates to my fields of study owing to the fact that biomimicry is multidisciplinary, interdisciplinary and transdisciplinary. The scholarly elements of the emerging biomimicry discipline are interrelated and mutually reinforcing. ${ }^{7}$ The practice of biomimicry is interdisciplinary by nature, involving the expertise not only of biological scientists, but also of social scientists, engineers, health professionals, designers, humanists, medical practitioners, business professionals and artists. Further, the ASU Biomimicry Center has formed interdisciplinary partnerships with Herberger Institute for Design and the Arts, College of Liberal Arts and Sciences, ASU School of Sustainability, W. P. Carey School of Business, ASU College of Health Solutions, Ira A. Fulton Schools of Engineering, and ASU School of Life Sciences. ${ }^{3}$

Meeting the ASU design aspiration "Fuse Intellectual Disciplines" will help me in the future by virtue of integrating this practice into my other career disciplines particularly behavioral health and health education. As an Interdisciplinary Post-Doc Scholar and Multidisciplinary Professor my mission is to motivate and educate. As a biomimicry scholar and biomimicry ASU Faculty Affiliate I am able to motivate and educate others in understanding the complex task of contributing locally and globally by producing academically honest and ethical health-related scholarly research at ASU. ASU is leading the way in biomimicry academia for the 21st century practitioner; the ASU Biomimicry Center transcends conventional academic boundaries by holistically engaging faculty, staff and students from multiple disciplines. This type of holistic approach presents biomimicry as a measure to achieve ecologically sustainable products and services that do not harm the environment through their production, usage or disposal. ${ }^{7}$

\section{Conclusion}

Biomimicry has monumental potential for innovation and education in medicine, health and wellness. The new thinking biomimicry graduate and research program is one of the emerging 
and innovative degree offerings at ASU and ASU Online that has bolstered the university to the top one percent of the world's most innovative prestigious universities. ${ }^{1}$ Moreover, as the number one university for innovation "ASU creates knowledge by transcending academic disciplines". ${ }^{8} 9$ My drive for fusing and working across disciplinary boundaries is fueled by the desire to help others with their overall physical and mental health. I have recently began integrating biomimicry into my geriatric practice by utilizing the biophilia hypothesis and biomimetic design to create nature inspired and nature emulated spaces for my students. At ASU and ASU Online, I have researched, studied and analyzed the biomimicry areas of bio-inspired design applied to healthier spaces and the human-nature connection emulated for health, well-being and healing. As a positive disruption in the field of healthcare and Western medicine, I look forward to learning more biomimicry applications from my ASU Faculty Affiliate colleagues. I pledge to continue advocating for the fusion of innovative transdisciplinary biomimicry models to improve the overall health outcomes of the ASU student population.

\section{Acknowledgments}

The author would like to thank Arizona State University and ASU Online for the resources utilized to develop this article. The author also acknowledges Professor Susie Zappia for her expert advice and critical feedback. The author appreciates the aforementioned entities, although they may or may not agree with the conclusions and interpretations of this opinion piece.

\section{Conflicts of interest}

Author declares that there are no conflicts of interest.

\section{Funding}

None.

\section{References}

1. Arizona State University. ASU Rankings. USA: Arizona State University; 2019a.

2. Arizona State University. Office of the President. Design Aspirations. USA: Arizona State University; 2019b.

3. Janine Benyus. Biomimicry - 6 Amazing Innovations Inspired by Nature. USA: Biomimicry 3.8; 2019.

4. Baumeister D. Biomimicry Resource Handbook: A Seed Bank of Best Practices. Biomimicry 3.8. 2013.

5. Benyus J. What is Biomimicry. 2014 .

6. Sharma S, Sarkar P. Biomimicry: Exploring Research, Challenges, Gaps, and Tools. In: Chakrabarti A, editor. Research into Design for a Connected World. Springer: Singapore; 2019. pp. 87-97.

7. Ivanić K, Tadić Z, Omazić MA. Biomimicry - An Overview. The Holistic Approach to Environment. 2015;5(1):19-36.

8. http://cf2015.bhcarroll.edu/files/session-2-toward-a-learning-century/asucase-example-outcomes-for-the-university.pdf

9. http://biomimicry.asu.edu 